\title{
Correction to: Study on pore size effect of low permeability clay seepage
}

\author{
Jian Chen ${ }^{1,2} \cdot$ Yingguang Fang ${ }^{1,2} \cdot$ Renguo $\mathrm{Gu}^{1,2} \cdot$ Haokai Shu ${ }^{1} \cdot$ Lingzhen $\mathrm{Ba}^{1,2} \cdot$ Wei Li $^{1}$
}

Published online: 10 May 2019

(C) Saudi Society for Geosciences 2019

Correction to: Arabian Journal of Geosciences (2019) 12:238. https://doi.org/10.1007/s12517-019-4375-3

The original version of this paper was published with error. Figures 12-17 were incorrectly processed during production typesetting. Given in this article are the correct figures.

The original article has been corrected.

The online version of the original article can be found at https://doi.org/ 10.1007/s12517-019-4375-3

Jian Chen

672445389@qq.com

1 School of Civil and Transportation Engineering, South China University of Technology, Guangzhou, China

2 State Key Laboratory of Subtropical Building Science, South China University of Technology, Guangzhou, China 


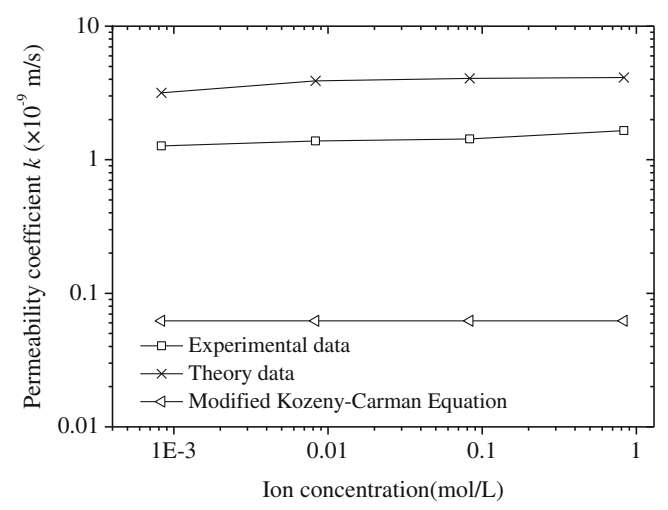

Fig. 12 Results of the natural clay measurements

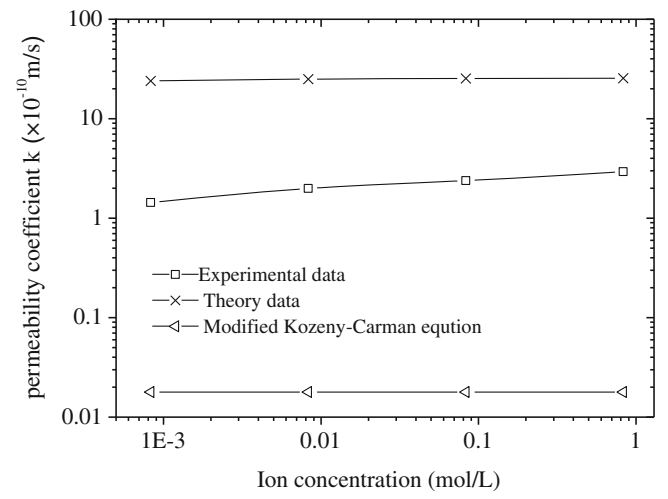

Fig. 13 Results of the artificial clay measurements

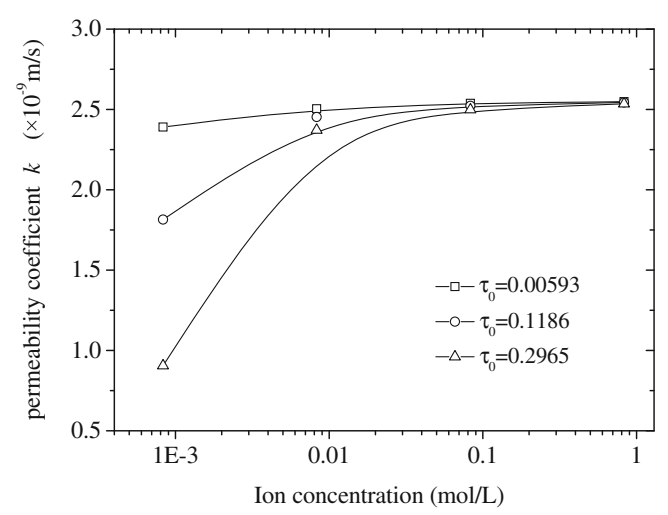

Fig. 14 Influence of $\tau_{0}$ on the permeability coefficient

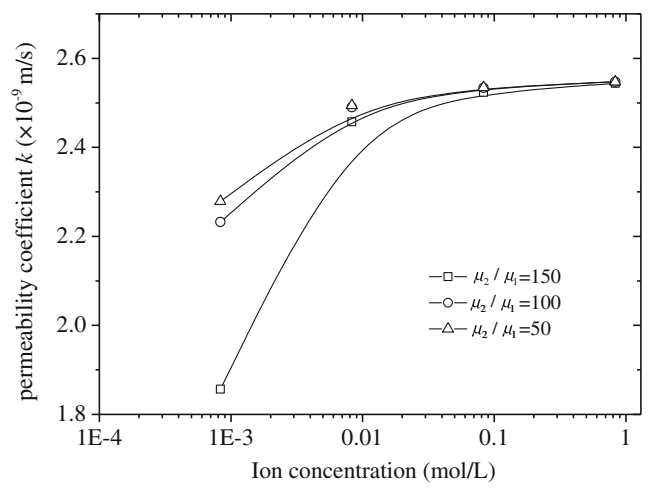

Fig. 15 Influence of $\mu_{2}$ on the permeability coefficient(Temperature $=$ $20{ }^{\circ} \mathrm{C}$ )

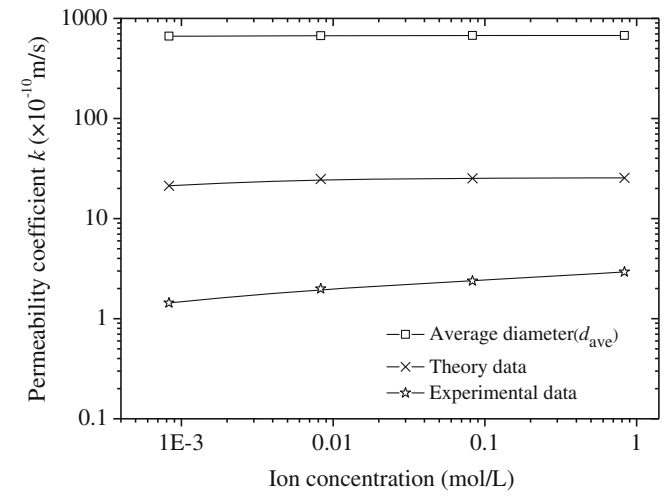

Fig. 16 Influence of the diameter calculation method on the permeability coefficient for artificial clay

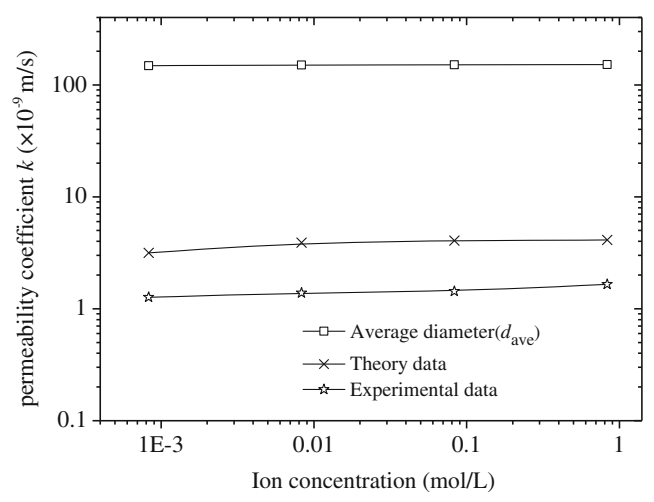

Fig. 17 Influence of th diameter calculation method on the permeability coefficient for natural clay 